\title{
Repertorios interpretativos en educación ambiental de docentes de instituciones educativas en el páramo de Pisba
}

\author{
Walter Pérez $\mathrm{Niño}^{1{ }^{\circledR}}$, Nancy Paola Montañez Aldana ${ }_{\text {Universidad Libre, Fundación Universitaria Iuan de Castellanos, Colombia }}^{\circledR}$
}

Autor de correspondencia: ${ }^{1}$ walter.perez@unilibre.edu.co Recibido: 15 de septiembre de 2020 Revisado: 26 octubre de 2020 Aprobado: 17 de abril de 2021 Publicado: 10 de junio de 2021

\section{Resumen}

En el artículo se analiza la educación ambiental en el páramo de Pisba, en primer lugar, a partir de algunas herramientas que pueden permitir a los educadores la consolidación de una cátedra de educación ambiental como la capacitación docente, una concepción amplia del ambiente, la enseñanza desde lo local hacia lo global, una postura crítica, su rol transformador, un carácter democrático-participativo, la transversalidad y la especificidad. Junto a ello, se presentan nociones paradigmáticas como las de derecho ambiental y la naturaleza como sujeto de derechos, como ejes que deben guiar la práctica educativa. En segundo lugar, se aplicó la metodología de análisis discursivo, enfocado hacia la identificación de repertorios interpretativos sobre educación ambiental de algunos docentes y directivos de municipios de la jurisdicción del páramo de Pisba. Para ello, se presenta la relación de los repertorios y de la educación ambiental a partir de las condiciones de las instituciones educativas, de los docentes, de los estudiantes y de sus familias, en una zona de riquezas naturales, explotación de recursos y conflictos ambientales, lo cual influye en la materialización de la educación ambiental y las visiones sobre el territorio y la justicia ambiental.

Palabras clave: educación, educación ambiental, medio ambiente, docente, repertorios interpretativos 


\title{
Interpretative repertoires in environmental education of schoolteachers in the Pisba páramo
}

\begin{abstract}
The article analyzes environmental education in the Pisba páramo, first of all, based on some tools that could allow educators to consolidate a course of environmental education, such as teacher training, a broad conception of the environment, teaching from the local to the global, a critical position, their transformational role, a democratic-participatory aspect, transversality, and specificity. In addition, paradigmatic notions such as environmental law and nature as a subject of rights are presented as axes that should guide the educational practice. Secondly, the methodology of discursive analysis was used, focused on the identification of interpretative repertoires on environmental education of some teachers and school administrators of municipalities in the jurisdiction of the Pisba páramo. To this end, we present the connection between repertoires and environmental education based on the conditions of educational institutions, teachers, students, and their families, in an area of natural wealth, resource exploitation, and environmental conflicts, all of which influences the implementation of environmental education and the perspectives on the territory and environmental justice.
\end{abstract}

Keywords: education, environmental education, environment, teacher, interpretative repertoires

\section{Repertórios interpretativos em educação ambiental de professores de instituições de ensino no páramo de Pisba}

\section{Resumo}

$\mathrm{O}$ artigo analisa a educação ambiental no páramo de Pisba, primeiramente, com base em algumas ferramentas que poderiam permitir aos educadores consolidar um curso de educação ambiental, como o treinamento de professores, uma concepção ampla do meio ambiente, o ensino do local ao global, uma posição crítica, seu papel transformador, um aspecto democrático-participativo, a transversalidade e a especificidade. Além disso, noções paradigmáticas como o direito ambiental e a natureza como sujeito de direitos são apresentadas como eixos que devem orientar a prática educacional. Em segundo lugar, foi utilizada a metodologia da análise discursiva, focada na identificação de repertórios interpretativos sobre educação ambiental de alguns professores e administradores escolares de municípios da jurisdição do páramo de Pisba. Para isso, apresentamos a relação entre repertórios e educação ambiental com base nas condições das instituições de ensino, dos professores, dos alunos e de suas famílias, numa área de riquezas naturais, exploração de recursos e conflitos ambientais, tudo isso influenciando a implementação da educação ambiental e as perspectivas sobre o território e a justiça ambiental.

Palavras-chave: educação, educação ambiental, meio ambiente, professor, repertórios interpretativos 
${ }^{1}$ El ser humano ha reconocido la importancia del ambiente para el desarrollo de la vida (Amador \& Esteban, 2011). No obstante, las preocupaciones sobre el ambiente se han exacerbado en las últimas décadas, en las que se ha hecho un llamado de atención sobre algunas problemáticas como la extinción de especies, el calentamiento global, el deterioro de la capa de ozono y la deforestación, entre otras (Avendaño, 2012).

Colombia es uno de los países más diversos del mundo ${ }^{2}$ (Calixto, 2010), lo que habla de su gran cantidad de riquezas ambientales y del atractivo que representa para la explotación irresponsable. De hecho, al igual que muchos países emergentes, el país ha adoptado un modelo que confía su economía a la extracción y a la exportación de los recursos naturales, dentro del modelo llamado "extractivista" (Gamba et al., 2012), con consecuencias lesivas importantes para el ambiente.

La explotación de recursos naturales ha generado conflictos ambientales entre distintos actores del territorio como empresas, trabajadores, gobernantes, movimientos sociales, etc. (Pérez-Rincón, 2016). Estas colisiones se pueden manejar y resolver si todos los actores cuentan con suficiente conocimiento sobre las causas y los efectos de las problemáticas y los mecanismos de participación. En este sentido, la educación juega un papel importante en la medida que sirve para empoderar a las personas como sujetos políticos, capaces de participar en la gestión de los conflictos y de proponer soluciones, de allí que el rol de los docentes sea fundamental para asegurar estos fines.

Este trabajo analiza los relatos y discursos sobre educación ambiental de algunos docentes y directivos docentes que laboran en instituciones educativas de la zona del páramo de Pisba, zona marcada por su riqueza ecosistémica y por la explotación de recursos naturales. Para ello, en primer lugar, el artículo explicará algunos aspectos relevantes en relación con la educación ambiental y expondrá conceptos como derechos del ambiente y derechos de la naturaleza. En segundo lugar, se presentará el método usado en este trabajo de investigación, el cual, bajo un enfoque cualitativo, se centra en la identificación de repertorios interpretativos (RI) que emergen de las entrevistas a profundidad a docentes y directivos de la zona. Finalmente, se examinarán las concepciones discursivas de estos docentes en relación con la construcción de la educación ambiental.

\section{Educación ambiental: la construcción de una cátedra sobre y para el ambiente}

El concepto sobre la educación ambiental ha cambiado a lo largo del tiempo. En sus inicios era asociada a la experiencia con la naturaleza. Luego se enfocó hacia actividades de conservación como el reciclaje (Sauvé, 1999)33. Actualmente es abordada desde distintas

\footnotetext{
1 Artículo producto de los proyectos de investigación Trabajadores de la cultura: Entre maestros, artistas, artesanos y deportistas. Garantía de los derechos sociales en Colombia (Universidad Libre) y El diálogo social como estrategia de desarrollo sostenible: resolución de conflictos medio ambientales: Caso de Estudio Páramo de Pisba en Boyacá (Fundación Universitaria Juan de Castellanos).

2 “Colombia es un país llamado 'mega-diverso' junto con Australia, Brasil, China, Ecuador, Estados Unidos de América, Filipinas, India, Indonesia, Madagascar, Malasia, México, Papúa Nueva Guinea, Perú, República Democrática del Congo, Sudáfrica y Venezuela” (Calixto, 2010, p. 27).

3 En los años 50 y 60, se determinaba como una educación para vivir en la naturaleza. En los años 70, se le da un nuevo enfoque que considera los problemas ambientales. En los años 80, se entiende el ambiente también como un proyecto comunitario que ha permitido dar nuevos significados. En los años 90, ha sido permeada por la educación para el desarrollo sustentable (Sauvé, 1999).
} 
aristas como: (1) una actividad que otorga conocimientos y actitudes que permiten entender dinámicas locales o globales (Riera et al., 2009); (2) un instrumento de sensibilización y cambio de actitudes sobre los problemas ambientales con perspectiva interdisciplinar (Ruiz, 2002); (3) una herramienta para entender las relaciones entre los sistemas naturales y sociales y; (4) una ética de la vida reformadora en valores y capaz de contribuir a la predicción de problemas (Avendaño, 2012).

No obstante, para que la educación ambiental pueda atender a las conceptualizaciones y fines con los que ha sido concebida, debe tener en cuenta algunos factores como: capacitación docente, una concepción amplia del ambiente, enseñar desde lo local hacia lo global, una postura crítica, su rol transformador, poseer un carácter democrático-participativo, la transversalidad y la especificidad. A continuación, se explicarán brevemente cada uno de ellos.

\section{Capacitación docente}

La capacitación convierte al docente en conocedor de su entorno y de los derechos humanos y de la naturaleza, autónomo, crítico frente a los discursos hegemónicos y un actor primordial en las realidades locales. Esta es necesaria para una renovación conceptual, metodológica y actitudinal, es decir, para construir un nuevo tipo de docente, capaz de reflexionar sobre su propia práctica y reorientarla (González-Muñoz, 1998).

\section{Concepción amplia del ambiente}

La enseñanza del ambiente requiere una visión amplia en tres sentidos. El primero tiene que ver con un enfoque sistémico que incluye elementos como el suelo, el agua, la atmósfera, las plantas, los animales y los microorganismos, así como las relaciones sociales, económicas y culturales que surgen en un territorio (Rodríguez et al., 2017). El segundo se relaciona con el ambiente sano como un derecho de todos sin discriminación (Vargas, 2006), el cual puede llegar a ser exigible judicialmente. Finalmente, el tercero recalca los nuevos discursos en los que se entiende el ambiente como sujeto de derechos que imponen límites para su explotación (Gudynas, 2010).

\section{Enseñar lo global y lo local}

Para entender la problemática ambiental, es necesario conocer el fenómeno global. En particular, los roles que juegan algunos países, bien como proveedores de materias primas, bien como transformadores de aquellas, y la forma en que las relaciones de poder entre los diversos actores públicos y privados afectan el ambiente en contextos específicos locales (Sousa, 2002). Así, por ejemplo, para entender los fenómenos del páramo de Pisba, es preciso comprender las lógicas de la política ambiental nacional, permeada por el rol del país en el contexto internacional.

\section{Postura crítica}

La educación ambiental debe involucrar una visión crítica sobre la mercantilización de la naturaleza (Ruiz, 2002), ya que algunos impactos de la actividad extractiva generan daños irreparables e injustos a las comunidades más vulnerables que se justifican sobre la idea de desarrollo. De esta manera, una postura crítica debe revisar esa noción de desarrollo, para verlo no solamente en términos de provecho económico de las empresas. Es preciso 
ampliarla e incluir en esta las nociones de bienestar social y económico de los seres humanos (Amador \& Esteban, 2011).

\section{Rol transformador}

La educación tiene que impartir valores y actitudes encaminadas hacia la participación, al involucrar el ambiente y las luchas populares en favor del cambio social (Carvalho, 1999; Ruiz, 2002). Es un elemento clave para la protección del ambiente, no solo desde las pequeñas acciones como el reciclaje, también desde los grandes cambios a partir de la acción política. Para ello es necesario que la educación genere conciencia en los sujetos sobre los problemas ambientales a través del diálogo con los estudiantes (Freire, 2007) y de la participación con la comunidad (Riera et al., 2009).

\section{Carácter democrático-participativo}

La educación ambiental debe involucrar un profundo sentido democrático que se concrete en: (1) la determinación de las políticas educativas por todos los sectores sociales; (2) la materialización de la educación ambiental formal e informal (Ruiz, 2002); (3) el empoderamiento de los actores mediante la educación ambiental para la participación en la política ambiental y los manejos del ambiente en el territorio (Rengifo et al., 2002), para tomar decisiones sin ser manipulados $;$ y (4) el pluralismo, ya que el carácter democrático de la educación ambiental implica una apertura a diversas ideas sobre el ambiente y el desarrollo, como las expuestas antes.

\section{Transversalidad y especificidad}

El ambiente tiene elementos biológicos, sociales y culturales, como ya se advirtió. Por ende, su estudio debe estar integrado de varias disciplinas (González-Muñoz, 1998), ya que la educación ambiental, además de ser necesaria como una cátedra autónoma, también debe permear los contenidos de otras materias.

Se puede concluir que la construcción de una cátedra sobre y para el ambiente requiere personal docente y directivo capacitado, con una visión amplia del ambiente y de los derechos asociados a este, que comprenda los contextos globales y locales, y capaz de empoderar a sus estudiantes con una perspectiva emancipadora para la participación democrática.

En Colombia existen varias disposiciones normativas que regulan y guían la educación ambiental, como la Constitución Política5 (1991), la Ley 99 de 1993 y la Ley 115 de 1994, que hablan de los derechos del ambiente y de la obligación de la adopción de planes y programas educativos de educación ambiental para generar conciencia y cambio de actitudes. No obstante, una de las normas más relevantes que regulan esta materia es la Ley 1549 de 2012, que tiene como propósito la institucionalización de la educación ambiental y ubica en las entidades territoriales el deber de destinar partidas presupuestales para su fomento. Dicha ley define a la educación ambiental como:

4 Existen personas que especialmente necesitan atención prioritaria dentro de la educación ambiental. En primer lugar, se encuentran las personas que toman decisiones sobre los recursos. En segundo lugar, son los adultos en general, ya que ellos toman pequeñas decisiones sobre comida, vestido y compras en general, que en últimas tienen grandes impactos. (Novo, 1998, p. 83)

5 Ver, por ejemplo, la sentencia de la Corte Constitucional C-431 de 2000, en la que se desarrolla el concepto de constitución ecológica. 
Un proceso dinámico y participativo, orientado a la formación de personas críticas y reflexivas con capacidades para comprender las problemáticas ambientales y sus contextos (locales, regionales y nacionales). Al igual que para participar activamente en la construcción de apuestas integrales (técnicas, políticas, pedagógicas y otras), que apunten a la transformación de su realidad, en función del propósito de construcción de sociedades ambientalmente sustentables y socialmente justas. (art. 1)

En Boyacá, la Ordenanza 021 de 2015 adopta un Plan decenal de educación ambiental en el que se reconocen problemas en cuanto a la baja participación y organización comunitaria, baja apropiación conceptual y metodológica para su enseñanza, poco afianzamiento con la educación no formal, acciones aisladas, sin profundidad y poco pertinentes para la capacitación de docentes (Cideaboy, 2015).

\section{Derecho ambiental y derechos de la naturaleza}

Son importantes para el análisis de la educación ambiental, en especial dentro del contexto elegido para la investigación, los conceptos de derecho ambiental y derechos de la naturaleza. Según estos, los seres humanos no solamente tienen un derecho a gozar de un entorno sano, sino que, además, los Estados deben reconocer que la naturaleza posee atributos intrínsecos que permiten entenderla como un sujeto de derechos. Así, estas dos concepciones, que han tenido acogida en los ordenamientos normativos gracias a la influencia del pensamiento de los pueblos indígenas de Latinoamérica, se involucran como grandes paradigmas que pueden guiar los fines y propósitos de la educación ambiental. A continuación, se explicarán en más detalle.

\section{Derecho ambiental}

Los derechos ambientales son reconocidos como derechos humanos de tercera generación. Son positivizados en distintos instrumentos jurídicos internacionales como derechos colectivos universales, de colaboración internacional, cuyo bien jurídico protegido afecta a un grupo indeterminado de personas que presentan un interés colectivo común (Muñoz, 2020).

El origen del derecho ambiental está situado, por una parte, en la Declaración de Estocolmo (Organización de las Naciones Unidas [ONU], 1972), la cual reconoce al medio ambiente como un derecho del ser humano, y en el Pacto Internacional de Derechos Económicos, Sociales y Culturales de 1966, que hace referencia a la necesidad de mejorar el medio ambiente como uno de los requisitos para el adecuado desarrollo de la persona. Para otros académicos, la génesis del derecho ambiental se encuentra en las reglas de Helsinki sobre el uso de aguas en ríos internacionales y en las primeras declaraciones del Consejo de Europa de 1968, relativas a la conservación del agua y la prevención de la contaminación del aire (Valbuena \& Reyes, 2012). Finalmente, otra parte de la doctrina estima que el derecho ambiental es tan antiguo como la humanidad porque las civilizaciones antiguas tenían normas para relacionarse con el ambiente (Cruz-Rodríguez, 2014).

La Declaración de Estocolmo (ONU, 1972) establece el derecho del ser humano a unas condiciones de vida satisfactorias en un ambiente cuya calidad le permita vivir con dignidad y bienestar, lo cual le impone asimismo "la solemne obligación de proteger y mejorar el medio ambiente para las generaciones presentes y futuras" (Principio 1). Otro de 
los hitos en la positivización internacional del derecho ambiental es la Declaración de Río (1992), donde se establecen unos principios que se constituyen en componentes básicos del desarrollo sostenible, entre los cuales están: el derecho de una vida saludable y productiva en armonía con la naturaleza. En este sentido, el derecho al medio ambiente adecuado o sano está vinculado a la idea de desarrollo sostenible, de tal forma que el desarrollo económico y social del hombre no ponga en peligro el hábitat humano (Muñoz, 2020).

En Colombia, los fundamentos del derecho ambiental se nutren de la positivización del derecho internacional. En la Constitución de 1991, llamada también la constitución ecológica, hay 34 artículos que hablan sobre temas ambientales, normativa que ha tenido desarrollo en un ordenamiento jurídico, unas políticas públicas y una institucionalidad que busca "asegurar el desarrollo sostenible y garantizar el derecho de todos los ciudadanos a gozar y heredar un ambiente sano" (Ministerio del Ambiente y Desarrollo Sostenible, 2020).

No obstante, el derecho ambiental reviste un fundamento antropocéntrico ${ }^{6}$, pues está orientado primordialmente a garantizar el bienestar humano o las condiciones que hacen posible la vida humana, al tener la protección a la naturaleza como un medio para conseguir ese fin (Cruz-Rodríguez, 2014). Esta base antropocéntrica puede comprenderse si se tiene en cuenta su vínculo con el concepto de desarrollo "sostenible" o "sustentable", con los cuales se planteó la necesidad de que el desarrollo no afecte el equilibrio de la biósfera ni comprometa la satisfacción de las necesidades de generaciones futuras.

El avance en la explotación y en la producción capitalista está superando la capacidad del planeta de soportar procesos que llevan implícito el daño ambiental, por lo que el desarrollo social no puede entenderse solamente desde el crecimiento económico (Sousa, 2014). Por lo tanto, son necesarios nuevos enfoques en los que se garantice un medio ambiente adecuado, la disponibilidad y la accesibilidad a recursos hídricos, la salud, la vida, la autodeterminación de los pueblos, entre otros. Las ideas de reciprocidad, solidaridad y complementariedad deben estar vigentes tanto en las relaciones entre los seres humanos como en las relaciones entre los humanos y la naturaleza.

\section{La naturaleza como sujeto de derechos}

En contraposición al paradigma antropocéntrico, surge el concepto de justicia ecológica, que plantea una visión biocéntrica, en busca de la protección y priorización de los derechos de la naturaleza y de la necesidad de considerarla como sujeto de derechos, sobre la base de su restauración y reparación, y no como hasta ahora, vista solo en función de las necesidades del ser humano. El otorgamiento de esta personalidad jurídica, y con ella el reconocimiento de derechos, responde, entre otros, a elementos de carácter ético basados en considerar a la naturaleza como un todo (Cruz-Rodríguez, 2014; Gudynas, 2009; Vallejo, 2019).

La Constitución ecuatoriana se convirtió en el principal referente jurídico para el constitucionalismo latinoamericano. Fue el primer texto que otorgó derechos a la naturaleza, como sujeto con reconocimiento jurídico. Impuso a los seres humanos la obligación de protección y defensa, ya que la naturaleza no puede actuar jurídicamente por sí misma. Esta constitución innova con la protección al medio ambiente en las constituciones locales, con

$6 \quad$ El fundamento antropocéntrico del derecho ambiental radica en que el sujeto de derechos continúa siendo el ser humano... El derecho ambiental reconoce el medio ambiente en tanto "bien jurídico" y de esa forma lo asocia con el concepto de "bienes colectivos" o con los derechos humanos. (Cruz-Rodríguez, 2014, p. 96) 
base en referencias tradicionales como Pachamama y buen vivir (Bonilla-Maldonado, 2019; Pinto et al., 2018).

La idea de naturaleza como sujeto de derechos descansa en la idea de sumak kawsay -o buen vivir-, que pregona la armonización de los seres humanos con la naturaleza, al ser uno de los elementos de la Madre Tierra (Antúnez-Sánchez \& Díaz-Ocampo, 2018). La naturaleza se concibe como el todo, como el organismo que hace posible la vida y es la vida misma. Lo engloba todo y, por ello, se considera sujeto de derechos omnicomprensivo y atemporal (Bonilla-Maldonado, 2019). Esta consideración implica el establecimiento de nuevas relaciones del ser humano con la naturaleza, en especial de carácter ético, con el fin de crear un nuevo contrato social, alejado de la concepción antropocéntrica tradicional, en donde la prioridad sea el rescate y la protección de la Pachamama (Antúnez-Sánchez \& Díaz-Ocampo, 2018). Particularmente esta teoría ha sido asimilada en Colombia a través de la Corte Constitucional en la sentencia T-622 de 2016 que ha influenciado, por ejemplo, al Tribunal Administrativo de Boyacá que declaró en 2018 al páramo de Pisba sujeto de derechos en el proceso 2018-0016.

\section{Metodología}

Para indagar los significados asociados a la educación ambiental, se utilizó la metodología de análisis del discurso, propuesto por Potter y Wetherell (1996), aplicada a la identificación de RI. Para ello, se realizaron seis entrevistas: tres a directivos y tres a docentes, cuatro mujeres y dos hombres, entre los 25 y 55 años de edad, profesionales con diversa experiencia laboral, de tres colegios públicos de zonas urbanas y rurales de algunos municipios dentro de la jurisdicción del páramo de Pisba. Esta diferencia indujo un análisis que, en algunos aspectos, permite distinguir diversas perspectivas narrativas sobre la educación ambiental en la región.

En las entrevistas se indagó sobre las estrategias pedagógicas de los docentes en materia ambiental. Se buscó centrar la atención en las experiencias significativas obtenidas por cada uno de ellos. La herramienta empleada como método de recolección de información fue la entrevista etnográfica, "entendida como una conversación a partir de la cual emergen los significados y las formas culturales presentes en el lenguaje, donde se manifiestan sentidos, valores y prejuicios, entre otras formaciones discursivas propias de una época y lugar concretos"7 (López et al., 2015, p. 1801).

El examen del material recogido se realizó a través de la metodología de análisis del discurso, que se enfoca en la identificación de los RI, para este caso, los relacionados con educación ambiental (López et al., 2015). Los RI se entienden como "elementos esenciales que los hablantes utilizan para construir versiones de las acciones, los procesos cognitivos y otros fenómenos, los cuales se encuentran constituidos por una restringida gama de términos que se repiten, en ocasiones a través de metáforas clave" (Potter \& Wetherell, 1996, p. 71). Es decir, los RI son mencionados reiteradamente por los entrevistados y configuran versiones mediante las cuales se significa y se construye la realidad.

7 En este tipo de entrevista, el investigador se convierte en un provocador de relatos que, antes de intentar conducir la narrativa, debe propiciarla y permitir al narrador reconstruir su historia en sus propios términos, los cuales son subjetivos y a la vez sociales. (López et al., 2015, p. 1801) 
Para el análisis de los RI, transcribimos las entrevistas. Luego, en sesiones de trabajo conjunto, se hizo una lectura de estas para buscar los elementos esenciales que los docentes utilizaron para construir sus explicaciones. En seguida, se realizaron análisis que caracterizaron los hallazgos de cada entrevista, con las siguientes categorías: condiciones de los establecimientos educativos, articulación de las escuelas con otras instituciones, contexto socioeconómico de las familias y de la región, educación ambiental, expectativas de vida de los estudiantes y justicia ambiental, territorio y derechos de la naturaleza (tabla 1). Después se discutieron los RI, al tener en cuenta sus características y contenido en busca de su relación con elementos del contexto social.

Tabla 1

Participación y coincidencia de los docentes en los RI

\begin{tabular}{|c|c|c|c|c|c|c|}
\hline \multirow{2}{*}{$\begin{array}{c}\text { Repertorios } \\
\text { Interpretativos }\end{array}$} & \multicolumn{6}{|c|}{ Entrevistados } \\
\hline & Docente 1 & Docente 2 & Docente 3 & $\begin{array}{l}\text { Directivo } \\
\text { docente } 1\end{array}$ & $\begin{array}{l}\text { Directivo } \\
\text { docente } 2\end{array}$ & $\begin{array}{l}\text { Directivo } \\
\text { docente } 3\end{array}$ \\
\hline $\begin{array}{l}\text { Condiciones de los } \\
\text { establecimientos } \\
\text { educativos }\end{array}$ & $\mathrm{X}$ & & $\mathrm{X}$ & $\mathrm{X}$ & $\mathrm{X}$ & $\mathrm{X}$ \\
\hline $\begin{array}{l}\text { Articulación de las } \\
\text { escuelas con otras } \\
\text { instituciones }\end{array}$ & $X$ & $\mathrm{X}$ & $\mathrm{X}$ & & $\mathrm{X}$ & \\
\hline $\begin{array}{l}\text { Contexto } \\
\text { socioeconómico de } \\
\text { las familias y región }\end{array}$ & & $\mathrm{X}$ & $\mathrm{X}$ & $\mathrm{X}$ & $\mathrm{X}$ & $\mathrm{X}$ \\
\hline Educación ambiental & $\mathrm{X}$ & $\mathrm{X}$ & $\mathrm{X}$ & $\mathrm{X}$ & $\mathrm{X}$ & $\mathrm{X}$ \\
\hline $\begin{array}{l}\text { Expectativas de vida } \\
\text { de los estudiantes }\end{array}$ & & $\mathrm{X}$ & $\mathrm{X}$ & $\mathrm{X}$ & $\mathrm{X}$ & $\mathrm{X}$ \\
\hline $\begin{array}{l}\text { Justicia ambiental, } \\
\text { territorio y derechos } \\
\text { de la naturaleza }\end{array}$ & & & $\mathrm{X}$ & $\mathrm{X}$ & $\mathrm{X}$ & \\
\hline
\end{tabular}

\section{Resultados}

El análisis de las entrevistas realizadas a docentes y directivos de municipios del Páramo de Pisba llevó al reconocimiento de cinco RI asociados a las instituciones educativas, condiciones de los estudiantes y sus familias, y finalmente, uno relacionado con la justicia ambiental y las apreciaciones sobre el territorio. Los RI son:

\section{Condiciones de los establecimientos educativos}

- Directivo docente: En contextos como el del páramo de Pisba, se presentan diferencias en relación con las zonas urbanas y rurales, y que los docentes en su mayoría no son del territorio. Vienen de otras zonas y hay mucha movilidad. En la ruralidad, bajo la modalidad de escuela nueva, un docente tiene que encargarse simultáneamente de varios grados al mismo tiempo, lo que demanda una exigencia mayor, mientras que en las zonas urbanas sí existe una división de materias, lo que puede traer desventajas.

El repertorio refleja un sentimiento de abandono de los docentes entrevistados, en especial en las zonas rurales. Ellos identifican problemas estructurales como infraestructura deficiente, falta de acceso a servicios públicos, carencia de vías, etc. Incluso narran que 
establecimientos han sido cerrados por la oficina de Gestión del Riesgo. También señalan algunos problemas que tienen los estudiantes en cuanto a nutrición y acceso a la institución, toda vez que los estudiantes deben caminar por horas. No obstante, estiman que la ruralidad permite una relación de confianza del profesor con el estudiante e incluso con las familias, lo cual incentiva la participación en el proceso educativo, a pesar de las debilidades de los padres. Para los docentes, en el casco urbano, debido a la concentración en un solo lugar, se facilita la coordinación, armonía y colaboración de la labor de enseñanza. Sin embargo, se presenta como debilidad la alta presencia de estudiantes flotantes por condiciones de migración.

\section{Articulación de las escuelas con otras instituciones}

- Directivo docente: Existen charlas esporádicas en fechas fijas como para el día del agua y otros días, pero no existe un programa sistemático y sostenible que apoye a la institución.

En este repertorio, los docentes expresaron falta de articulación entre instituciones educativas y entidades públicas ambientales. Ellos agradecen la colaboración institucional de Corpoboyacá y Parques Nacionales, pero sostienen que esta se reduce a la celebración de fechas especiales como el Día del Agua, o por medio de capacitaciones e invitaciones a concursos sin un seguimiento constante. También reconocen que Parques Nacionales además ha apoyado algunos proyectos de escuelas rurales.

De igual forma, se expresa que los habitantes de la zona no confían en estas instituciones, debido a que las exigencias de estas chocan con las prácticas locales. No obstante, se resalta la motivación del personal docente en la participación de los concursos organizados por Corpoboyacá. Incluso existen experiencias significativas como el proyecto ACHAWASGuardianes del Medio Ambiente de la escuela vereda Pueblo Viejo, del municipio de Socotá, ganadores del premio Espeletia Dorada, versión 2018.

En el caso de las alcaldías municipales y de la gobernación, se piensa que el apoyo es menor para las escuelas, en especial para las rurales, aunque destacan la celebración del bicentenario. Se resalta, igualmente, que políticas tomadas en algunos municipios, como la de separar los residuos, han servido como incentivo para la educación ambiental.

Finalmente, una de las cuestiones que se pueden subrayar del análisis del discurso en este RI es el vacío en la integración de otros actores, por ejemplo, los movimientos sociales.

\section{Contexto socioeconómico de las familias y de la región}

- Directivo docente: En la mayoría de los municipios donde se hace extracción de carbón, se habla de sostenibilidad y los líderes mineros hacen algunas donaciones, pero no existe equilibrio entre el daño que se hace con la extracción del carbón y el ambiente. Se está afectando el agua, el ambiente, el aire y, por lo tanto, no existe un equilibrio de sostenibilidad de la parte ambiental.

- Directivo docente: Los estudiantes ven como su medio de ingreso el trabajo en las minas. Incluso algunos no continúan estudiando por trabajar en las minas.

Los docentes dejan ver la gran influencia de la minería en el sector, ya que es el principal renglón económico en la zona. Estos ven cómo las familias dependen de forma directa e 
indirecta de la extracción de carbón y consideran esta actividad como una oportunidad de mayores ingresos, a pesar del reconocimiento de los daños ambientales que genera. Además, identifican que otras actividades como la agricultura no son bien remuneradas, lo que impacta en las proyecciones a futuro de los menores. La consecuencia de ello es que los chicos se dediquen a la parte minera, por lo que cambian la manera de pensar en cuanto a las preocupaciones aprendidas sobre el ambiente.

Además, los docentes dejan ver la diversidad de la comunidad educativa. En las aulas puede haber hijos de los dueños de minas, niños desplazados y niños que hacen parte de la población flotante. En particular, estos últimos sufren interrupciones o alteraciones en los procesos de enseñanza.

\section{Educación ambiental}

- Docente: Mejorar la educación depende de la pasión del docente y del gusto. No de docentes que se sienten obligados.

- Directivo docente: La institución busca que las experiencias significativas en el cuidado del medio ambiente de algunos profesores se compartan con otros profesores y otras instituciones.

- Directivo docente: La educación en temas ambientales debe empezar por concientizar a los más pequeños, en programas como separación de residuos y cuidado del medio ambiente.

- Directivo docente: Se están empezando a transversalizar los proyectos ambientales pero la movilidad de los docentes afecta el proceso. De igual forma, los docentes que trabajan en el área ambiental capacitan a los demás.

- Docente: El mayor problema que se ha presentado con los estudiantes es la concientización de cada uno de ellos, ya que es muy difícil que empiecen por ellos mismos, por ejemplo, no botar la basura en el patio del colegio, sino botarla en la cesta que corresponde.

El RI hace evidente que, a pesar de ser una zona de páramo, no todos los establecimientos tienen como eje central el ambiente o lo agropecuario. Esto se podría explicar en la búsqueda de nuevos enfoques, ya que el poco apoyo a estos sectores tradicionales ocasiona la falta de interés de las generaciones por realizar este tipo de actividades.

Las instituciones desarrollan actividades de educación ambiental asociadas a los PRAE - proyectos ambientales escolares - en cumplimiento de los lineamientos dados por el Ministerio de Educación y la Secretaría de Educación departamental. Estos proyectos están enfocados en instituciones de la parte urbana en torno al manejo de residuos, reciclaje y reutilización de desechos. En la parte rural, se aborda este tema, pero también se enseña a partir de huertas escolares. Asimismo, se indica que en territorios de páramos se hace énfasis en el cuidado de las fuentes hídricas y la reforestación. Otras estrategias están dadas en proyectos de grado en educación media o cumplimiento de horas sociales con elección del ambiente como eje. Sin embargo, estos últimos son casos aislados sin apoyo financiero. También se identifican mayores dificultades en las zonas rurales, por lo que la educación depende del estatus socioeconómico de las personas. 
Para los entrevistados, con la educación se quiere buscar que los estudiantes identifiquen qué es lo que pasa a su alrededor y cómo pueden aportar para que la situación mejore, al indicar las consecuencias a futuro si no se actúa. No obstante, es necesaria la generación de proyectos para motivar a los estudiantes, quienes están condicionados por la actividad económica que les permite tener un bienestar que no consiguen en condiciones normales, más cuando se encuentran marginalizados. Allí se diluye el discurso sobre la preservación del ambiente.

\section{Expectativas de vida de los estudiantes}

- Docente: Los niños no tenían sueños. No sabían responder qué querían ser cuando sean grandes, pero, por intermedio de gestión, se pueden crear experiencias y, de acuerdo con ello, ya mejoran sus ideas frente al futuro.

Este RI muestra las perspectivas de futuro que tienen los estudiantes de la zona. Así, la minería es para muchos su opción de vida, gracias a la influencia familiar y del entorno. Esto se acentúa cuando los estudiantes trabajan en vacaciones o por periodos cortos en las minas y tienen la posibilidad de obtener ingresos que invierten en tecnología o diversión. Sin embargo, algunos egresados del casco urbano han podido ingresar a la educación superior, situación que permite pensar en una transformación social a partir de los procesos de educación superior.

A su vez, desde los establecimientos educativos, consideran fundamental el trabajo en proyectos de vida que permitan cambiar expectativas en los alumnos y fortalecer la toma de decisiones, en especial para enfrentar el desplazamiento hacia las ciudades en donde realizarán sus estudios universitarios o para contemplar aspiraciones distintas a la minería.

\section{Justicia ambiental, territorio y derechos de la naturaleza}

- Docente: El territorio es la tierra y la gente. Las comunidades y su cultura, cómo se alimentan, hace parte del territorio. Las comunidades lo ven más como sinónimo de propiedad.

- Directivo docente: Los derechos ambientales son los de la propia naturaleza y también tienen que ver con vivir en un entorno saludable y lleno de vida.

En este repertorio se reconocen derechos de la naturaleza y de vivir en un entorno saludable que privilegie el ambiente por encima de la explotación y que considere el páramo como riqueza natural y fuente de agua. Para ello, en algunas zonas se apoyan de voluntarios expertos en temas ambientales, quienes ayudan al reconocimiento del territorio en el mismo territorio. Esta tarea resulta fundamental, en especial en una realidad en donde las comunidades rurales llevan una mala relación con las entidades ambientales, porque no ha habido pedagogía con los habitantes de estas zonas. La falta de comunicación genera desinformación.

Los docentes y directivos docentes en su mayoría no tienen conocimientos profundos en relación con los derechos ambientales y con conceptos como territorio, justicia ambiental y derechos de la naturaleza. 


\section{RI y educación ambiental}

Los discursos de docentes y directivos docentes muestran que la educación ambiental tiene tres componentes importantes en el territorio del páramo de Pisba. El primero es el enfoque clásico en que se enseña la recolección de residuos y tiene énfasis en las zonas urbanas. La segunda es la educación agropecuaria que se enfoca mayormente en las zonas rurales. Esta abarca el manejo de cultivos e incluye concepciones más modernas sobre métodos y manejo de recursos. En tercer lugar, está la trasversalidad en una etapa inicial, pero que promete expandirse cada vez más en el sistema educativo. No obstante, el desarrollo de estas prácticas educativas choca con las realidades locales; por una parte, con la precariedad de los recursos de las instituciones que limitan los ámbitos de la enseñanza; y por otra, con el modelo del desarrollo económico, en donde la agricultura es poco patrocinada y las actividades de explotación son mejor remuneradas. Las dinámicas económicas, en últimas, terminan sometiendo las actividades de los estudiantes a las actividades de explotación, con los impactos provocados en el ambiente.

En ese sentido, la labor docente en los municipios del páramo implica una doble dimensión y función. Así, además del ejercicio educativo y de formación estudiantil en sus áreas de especialidad, está el empoderamiento como sujetos políticos para el respeto y rescate del ambiente desde lo local hacia lo global, aunque esta labor se vea obstruida por los modelos de desarrollo económico en la región.

Asimismo, los RI evidencian una sensibilidad en los discursos de los docentes sobre las responsabilidades en relación con el respeto por el ambiente. Sin embargo, hay debilidad en su mayoría en el manejo de conceptos como territorio, derechos ambientales y derechos de la naturaleza. Esto evidencia la necesidad de una mayor capacitación por parte de las autoridades respectivas.

Otra debilidad es la falta de articulación sólida con las entidades estatales. Con algunas, como los entes territoriales, no existe vínculo. Con otras, como Corpoboyacá y Parques Nacionales, hace falta mayor coordinación para que las actividades se ejecuten en planes de educación ambiental, que lleguen a estudiantes y padres, que no sean esporádicos y que creen confianza en la ciudadanía. En esa vía, también es necesario el fortalecimiento de las relaciones entre la escuela y las comunidades, para el seguimiento y apoyo permanente de los procesos relacionados con el ambiente en los municipios.

De esta manera, se requiere romper los paradigmas de educación tradicionales con la implementación de la dimensión ambiental dentro del currículo de una manera transversal, al adaptar los métodos y contenidos educativos a la solución de problemáticas específicas relacionadas con el ambiente local. Para ello, es imprescindible capacitar a los docentes, con el fin de que aborden desde un punto de vista sistémico las consecuencias locales de la explotación de recursos naturales y del cambio climático, teniendo en cuenta el rol transformador que ejercen al promover en los estudiantes y sus familias la adopción de modos de vida desde una perspectiva de desarrollo sustentable con la adecuada utilización de recursos naturales. Asimismo, es importante buscar alternativas inclusivas que procuren cambiar el modelo de desarrollo extractivista de la comunidad que habita en ecosistemas estratégicos como el páramo de Pisba. 


\section{Conclusiones}

La educación ambiental no debe entenderse solamente como una asignatura; debe abordarse a profundidad en cada una de las áreas impartidas en las instituciones educativas. Allí los retos tienen que proyectarse hacia el logro de políticas integrales que permitan un enfoque dirigido hacia la planeación y ejecución de proyectos transversales, los cuales logren implementar pedagogías transformadoras y brindar herramientas suficientes en pro de mejorar la calidad de vida de los estudiantes y de la región.

De manera particular, la educación ambiental en las instituciones educativas del territorio del páramo de Pisba busca ser un instrumento de sensibilización y cambio de actitudes sobre las problemáticas ambientales en los estudiantes y en la comunidad a su alrededor. Además, procura ser una herramienta para entender las relaciones entre los sistemas naturales y sociales. No obstante, existen algunas debilidades y obstáculos.

Aunque han ocurrido experiencias significativas en el desarrollo de proyectos ambientales, estas son aisladas y, muchas veces, limitadas por el entorno socioeconómico, por lo que los resultados de la pedagogía ambiental, en general, solo se quedan en una pretensión de cambio social. Además, para que la educación ambiental cumpla con su propósito, es imprescindible que los docentes reciban una capacitación en la que conozcan los nuevos conceptos sobre el ambiente y los contextos globales y locales que lo afectan. Asimismo, esta no solamente tiene que ir orientada a aquellos profesores que manejan áreas como ciencias naturales, sino a todos, ya que esta educación no solo requiere un área específica sino su impartición de forma transversal.

Ahora bien, dentro de la capacitación se deben tener en cuenta los discursos sobre el ambiente sano, como derecho que se debe respetar y que es indispensable para la supervivencia del ser humano y de las futuras generaciones. Igualmente, es relevante tener en consideración las nuevas concepciones que entienden a la naturaleza como sujeto de derechos y, en ese sentido, pensar en el ser humano con una visión más biocéntrica que antropocéntrica.

Los RI de los docentes y directivos reflejan que, aunque intentan realizar ejercicios para la consolidación de la educación ambiental, es necesario mayor apoyo por parte de los entes gubernamentales. Es preciso fomentar proyectos productivos amigables con el ambiente, en los que además los educandos se puedan proyectar por fuera de la institución educativa cuando terminen sus estudios, como alternativa a empleos en la industria extractiva.

Entender la educación ambiental desde una óptica ética, con capacidad para contribuir a la predicción de problemas, genera retos en el rol docente. En el caso de los municipios del páramo de Pisba, con alta presencia de extracción minera y dependencia económica de las familias a esta actividad, hay una disyuntiva respecto al cuidado y preservación de los recursos naturales, reflejada en la difícil participación y concienciación de los estudiantes y padres de familia frente al tema, así como en la presencia de expectativas de vida asociadas al trabajo minero, en especial, por la facilidad de ingresos económicos superiores respecto a otras actividades. 


\section{Referencias}

Amador, L., \& Esteban, M. (2011). Desde la educación social a la educación ambiental. Hacia una intervención educativa socioambiental. Revista de Humanidades, 18, 147. https://doi.org/10.5944/rdh.18.2011.12885

Antúnez-Sánchez, A., \& Díaz-Ocampo, E. (2018). El pluralismo jurídico y los derechos a la Pachamama. Dixi, (27). https://doi.org/10.16925/di.v20i27.2398

Avendaño, W. (2012). La educación ambiental (EA) como herramienta de la responsabilidad social (RS). Revista Luna Azul, 35, 94-115. https://www.redalyc.org/ pdf/3217/321727349006.pdf

Bonilla-Maldonado, D. (2019). El constitucionalismo radical ambiental y la diversidad cultural en América Latina. Los derechos de la naturaleza y el buen vivir en Ecuador y Bolivia. Revista Derecho del Estado, (42), 3-23. https://doi.org/10.18601/01229893. $\mathrm{n} 42.01$

Calixto, R. (2010). Educación popular ambiental. Trayectorias, 12(30), 24-39.

Carvalho, I. (1999). La cuestión ambiental y el surgimiento de un campo educativo y político de acción social. Tópicos de Educación Ambiental, 1(1), 27-33.

Cideaboy. (2015). Plan departamental de educación ambiental de Boyacá 2015-2025. http://sedboyaca.gov.co/wp-content/uploads/files/Plan Departamental de Educación Ambiental 2016-2015\%281\%29.pdf

Congreso de la República de Colombia. (1993, 22 de diciembre). Ley 99. Por la cual se crea el Ministerio del Medio Ambiente, se reordena el Sector Público encargado de la gestión y conservación del medio ambiente y los recursos naturales renovables, se organiza el Sistema Nacional Ambiental, SINA y se dictan otras disposiciones. Diario Oficial 41146. http:// www.secretariasenado.gov.co/senado/basedoc/ley_0099_1993.html

Congreso de la República de Colombia. (1994, 8 de febrero). Ley 115. Por la cual se expide la Ley General de Educación. Diario Oficial 41214. https://bit.ly/3237N87

Congreso de la República de Colombia. (2012, 5 de julio). Ley 1549. Por medio de la cual se fortalece la institucionalización de la política nacional de educación ambiental y su incorporación efectiva en el desarrollo territorial. Diario Oficial 48482. http://www. secretariasenado.gov.co/senado/basedoc/ley_1549_2012.html

Constitución Política de Colombia. (1991). Presidencia de la República de Colombia. http:// wsp.presidencia.gov.co/Normativa/Documents/Constitucion-Politica-Colombia.pdf

Corte Constitucional, Sala Sexta (2016, 10 de noviembre) SSentencia T-622. Expediente T-5.016.242. (J. I. Palacio Palacio, M. P.).

Corte Constitucional, Sala Plena (2000, 12 de abril) Sentencia C-431. Expediente D-2589. (V. Naranjo Mesa, M. P.).

Cruz-Rodríguez, E. (2014). Del derecho ambiental a los derechos de la naturaleza: sobre la necesidad del diálogo intercultural. Jurídicas, 11(1), 95-116.

Freire, P. (2007). La pedagogía del oprimido. Siglo XXI. 
Gamba, G., Fuentes, H., \& Contreras, L. (2012). Efectos de la inversión extranjera en la actividad minera colombiana y de cuatro países de la región. Apuntes de CENES, 31(53), 51-79.

González-Muñoz, M. (1998). La educación ambiental y formación del profesorado. Revista Iberoamericana de Educación, 16(16), 13-22. https://doi.org/10.35362/rie1601109

Gudynas, E. (2009). La dimensión ecológica del buen vivir: entre el fantasma de la modernidad y el desafío biocéntrico. OBETS. Revista de Ciencias Sociales, (4), 49-53.

Gudynas, E. (2010). La senda biocéntrica: valores intrínsecos, derechos de la naturaleza y justicia ecológica. Tabula Rasa, 13, 45-71. https://doi.org/10.25058/20112742.404

López, O., Vargas, L., Covelli, C., Pérez, M., \& Santamaría, L. (2015). Sindicalismo y trabajo: la experiencia de los jóvenes bogotanos desde sus repertorios interpretativos. Universitas Psychologica, 14(5), 1795-1808. http://dx.doi.org/10.11144/Javeriana.upsy14-5.hcva

Ministerio del Ambiente y Desarrollo Sostenible (2020, 18 de abril). Misión y visión. https:// www.minambiente.gov.co/index.php/ministerio/mision-y-vision.

Muñoz, E. (2020). El medio ambiente como bien jurídico protegido desde roma y derecho humano de tercera generación [Conferencia]. III Congreso Virtual Internacional sobre Economía Social y Desarrollo Local Sostenible. España.

Novo, M. (1998). La educación ambiental formal y no formal: dos sistemas complementarios. Revista Iberoamericana de Educación, 11, 75-102.

Organización de las Naciones Unidas. (1972). Declaración de Estocolmo. http://www.upv.es/ contenidos/CAMUNISO/info/U0579218.pdf

Pérez-Rincón, M. (2016). Caracterizando las injusticias ambientales en Colombia: Estudio para 115 casos de conflictos socio-ambientales. MA-CA, Univalle.

Pinto, I., Cerneiro, P., Silva da, S., \& Maluf, F. (2018). La naturaleza como sujeto de derechos: análisis bioético de las constituciones de Ecuador y Bolivia. Revista Latinoamericana de Bioética, 18(1), 155-171. https://doi.org/10.18359/rlbi.3030

Potter, J., \& Wetherell, M. (1996). El análisis de discurso y la identificación de los repertorios interpretativos. En A. Gordo \& J. Linaza (Eds.), Psicologías, discursos y poder (pp. 63-78). Visor.

Rengifo, B., Quitiaquez, L., \& Mora, F. (2002). La educación ambiental, una estrategia pedagógica que contribuye a la solución de la problemática ambiental en Colombia. http:// www.ub.edu/geocrit/coloquio2012/actas/06-B-Rengifo.pdf

Constitución Política de Colombia. (1991). Presidencia de la República de Colombia. http:// wsp.presidencia.gov.co/Normativa/Documents/Constitucion-Politica-Colombia.pdf

Riera, L., Sansevero, I., \& Lúquez, P. (2009). La educación ambiental: un reto pedagógico y científico del docente en la educación básica. Laurus, 15(30), 392-406.

Rodríguez, C., Rodríguez, D., \& Durán, H. (2017). La paz ambiental: retos y propuestas para el posacuerdo. Dejusticia.

Ruiz, J. (2002). Movimientos sociales y educación ambiental. Cooperación Educativa, 64, 13-29. 
Sauvé, L. (1999). La educación ambiental entre la modernidad y la posmodernidad: en busca de un marco de referencia educativo integrador. Tópicos en Educación Ambiental, 1(2), 7-26.

Sousa de, B. (2002). Hacia una concepción multicultural de los derechos humanos. El Otro Derecho, 28, 58-83.

Sousa de, B. (2014). Derechos humanos, democracia y desarrollo. Centro de Estudios de Derecho, Justicia y Sociedad.

Valbuena, J., \& Reyes, G. (2012). Elementos de control, gestión y auditoría medioambiental. Universidad Externado de Colombia.

Vallejo, S. (2019). La considerabilidad moral: fundamento ético del reconocimiento de la naturaleza como sujeto de derecho. Letras Verdes. Revista Latinoamericana de Estudios Socioambientales, (26), 11-34. https://doi.org/10.17141/letrasverdes.26.2019.3913

Vargas, J. (2006). Los nuevos movimientos sociales y el medio ambiente. Revista Venezolana de Ciencias Sociales, 10(1), 37-54. 